\title{
Original Research \\ Cytofluorimetric assay to investigate variability in blinatumomab in vitro response
}

\author{
Stefania Braidotti ${ }^{1}$, Raffaella Franca ${ }^{1}$, Marilena Granzotto ${ }^{2}$, Elisa Piscianz ${ }^{3}$, \\ Alberto Tommasini ${ }^{1,3}$, Marco Rabusin ${ }^{3}$, Gabriele Stocco ${ }^{4}$, Giuliana Decorti ${ }^{1,3, *}$ \\ ${ }^{1}$ Department of Medical, Surgical and Health Sciences, University of Trieste, 34149 Trieste, Italy \\ ${ }^{2}$ Azienda Sanitaria Universitaria Giuliano Isontina (ASUGI), 34148 Trieste, Italy \\ ${ }^{3}$ Institute for Maternal \& Child Health (I.R.C.C.S) Burlo Garofolo, 34137 Trieste, Italy \\ ${ }^{4}$ Department of Life Sciences, University of Trieste, 34127 Trieste, Italy \\ *Correspondence: decorti@units.it (Giuliana Decorti) \\ Academic Editor: Yingqun Wang and Haihua Feng \\ Submitted: 25 October 2021 Revised: 19 December 2021 Accepted: 20 December 2021 Published: 24 January 2022
}

\begin{abstract}
Background: The T-cell engager antibody blinatumomab (Blincyto ${ }^{T M}$ ) represents a promising rescue therapy for relapsed/refractory $\mathrm{CD} 19^{+}$acute lymphoblastic leukemia (B-ALL), although $\sim 20-30 \%$ of patients still do not respond to treatment. Blinatumomab creates a tight synapsis between $\mathrm{CD} 3^{+} \mathrm{T}$-lymphocytes and leukemic $\mathrm{CD} 19^{+} \mathrm{B}$-cells, resulting in a granzyme $\mathrm{B}(\mathrm{GzB})$-mediated specific lysis of leukemic cells. Methods: Aim of the study was to provide evidence that variability in blinatumomab response could have a genetic basis in PAX5, one of the most often mutated genes in B-ALL, affecting the CD19 surface expression on lymphoblasts, and could be explored in vitro by means of a cytofluorimetric assay, staining both surface antigens (CD45, CD19 and CD3) and intracytoplasmic markers (7AAD, Syto16). Two human immortalized B-ALL cell lines (NALM6 and REH) were chosen for their different PAX5 and CD19 protein levels, as verified by western blot and flow cytometry, respectively. Results: In contrast to NALM6, REH cells do not express the full-length PAX5 protein and show less CD19 on the cell surface (fluorescence peak median intensity: 9155 versus 28895). Co-cultures of $\mathrm{CD}^{+}$T-lymphocytes from healthy donors and B-ALL cell lines were seeded at an effector-to-target cell ratio of 1:10 for simulating the condition existing in the bone marrow due to the malignant invasion of blast cells. Co-cultures were exposed in vitro to blinatumomab and the simultaneous increase in blast mortality and T-lymphocytes activation induced by the drug was observed at day +7 (both effects: $p<0.0001$ versus untreated, two-way ANOVA, Bonferroni post-test), and was particularly pronounced in REH compared to NALM6 co-cultures $(p<0.05)$. Surprisingly, daily release of GzB in supernatants, measured by an ELISA assay, was significantly lower in drug-exposed REH co-cultures compared to NALM6 at early time-points (days +3 and $+4, p$-value $<0.0001$, three-way ANOVA), reaching a comparable plateau only towards the end of the incubation period (at day +5$)$. Only 2 out of 5 primary co-cultures of leukemic and mononuclear cells isolated from bone marrow aspirates of B-ALL patients (age: median 10.7 years, interquartile range (IQR) 3.4; males: $60 \%$ ) responded to the drug in vitro (simultaneous blast mortality and T-lymphocyte activation: both effects: $p<0.0001$ versus untreated) and at different drug concentrations. Results were unrelated to the percentages of immature CD19 ${ }^{+}$B-cells in the diagnostic samples. Conclusions: In conclusion, cytofluorimetric analysis can highlight the different response induced by blinatumomab among co-cultures. Whether and how this difference is affected by PAX5-regulated CD19 expression is unclear and whether it is predictive of in vivo response to therapy remains to be established. Further dedicated studies are required to investigate these issues in detail.
\end{abstract}

Keywords: Pediatric acute lymphoblastic leukemia; Blinatumomab; In vitro cytofluorimetric assay; PAX5

\section{Introduction}

Acute lymphoblastic leukemia (ALL), in particular B-cell precursor ALL, is the most frequent hematological malignant neoplasm occurring during childhood, with a peak incidence between 1 and 4 years of age. The standard ALL therapy lasts 24 months and therapeutic protocols comprise different chemotherapeutic and immunosuppressive agents [1]. Although often burdened by severe side effects, fist-line polychemotherapeutic approaches result in clinical remission in most pediatric patients (5-year survival rate approximately $80 \%$ ) [2-4]. In contrast, ALL could be fatal in $\sim 50-60 \%$ of children with recurrence [5]. In relapsed/refractory ALL, haematopoietic stem-cell transplantation might represent the only curative option; however, this clinical procedure requires bone marrow remission that is not easily achievable in patients who already failed to respond to pharmacological treatments [6]. A relevant ongoing approach in ALL therapeutic protocols is the introduction of new biological drugs, which should be integrated in salvage therapy to further improve rescue outcome. Among these, there is the bispecific T-cell engager (BiTE) antibody construct blinatumomab (Blincyto $^{T M}$ ) [7]. Blinatumomab is a single peptide with a molecular weight of $\sim 55 \mathrm{kDa}$ and consists of two antibody single chain variable fragments (one against the surface antigen CD3 and one against CD19) joined by a flexible 
glycine-serine linker. Blinatumomab acts as a shortadapter molecule that forces mature $\mathrm{CD}^{+}$cells (T-lymphocytes) and $\mathrm{CD} 19^{+}$tumor $\mathrm{B}$ cells into close proximity, creating a tight cell-specific synapse that induces a strong T-cell activation and proliferation. Effector cells $\left(\mathrm{CD}^{+}\right)$are thus able to recognize leukemic blasts and induce their death by apoptosis, through the release of perforins and granzymes [8]. Blinatumomab has been administered with success in relapsed/refractory B-ALL adult cases. However, primary resistance has been observed in $20-30 \%$ of adult patients [6]. Recently, two international randomized clinical trials (www.clinicaltrials.gov; identification numbers: NCT02101853 and NCT02393859) clearly demonstrated the benefit of blinatumomab in terms of overall survival in pediatric patients with high-risk first relapse of B-ALL with chemotherapy-responsive disease. Blinatumomab was administered in combination with conventional chemotherapy and compared to conventional chemotherapy alone. Importantly, blinatumomab showed a favorable toxicity profile, with less life-threatening complications $[9,10]$.

The role of CD19 in therapy failure with blinatumomab has been hypothesized and investigated to clarify whether blinatumomab exposure exerts a potent selective pressure, resulting in a CD19 negative recurrence; controversial conclusions on this issue were reported [11,12]. CD19 is a co-stimulatory type I transmembrane protein ( $\sim 95 \mathrm{kDa}$ ), exclusively expressed on B-cells. It functions as a critical co-receptor of the B-Cell Antigen-Receptor (BCR) signal transduction pathway. In particular, CD19 mediates the activation of the Src family protein-tyrosine kinases, such as Lyn and Fyn [13], that enhance BCR-induced signaling through recruitment and activation of PI3K and downstream Akt kinases, thus promoting B-cells survival and cell growth [14]. The CD19 gene contains a binding site for the B-cell lineage specific activator protein (BSAP) in its promoter's region, and the expression of CD19 is reduced in pre-B-cells deficient in BSAP [15]. BSAP is encoded by the PAX5 gene and is the only PAX protein expressed in the hematopoietic system. The protein functions both as a transcriptional activator and as a repressor on different target genes involved in B lymphoid lineage development $[16,17]$. Interestingly, genomic and transcriptomic analyses in pediatric and adult B-ALL identified $P A X 5$ as one of the most often mutated genes in leukemic cells, being involved in several leukemia-associated rearrangements, such as gene fusions ( $2-3 \%$ of ALL cases) or intragenic amplifications [18-20]. Moreover, several somatic point mutations at the level of the $P A X 5$ exonic sequence, influencing the different structural domains and functions of BSAP, have been identified in over $30 \%$ of ALL cases [19,21]. The genetic basis of interpatient variability in blinatumomab response have not been investigated so far. The aim of this study was thus to provide evidences of the hypothesis that a differential CD19 surface density on B-ALL cells, due to a heterogeneous $P A X 5$ genetic background, could affect blinatumomab response. Therefore, co-cultures of T-lymphocytes from healthy donors and lymphoblastic BALL cell lines (with a different $P A X 5$ genetic status) were maintained in the presence of blinatumomab for one week. Cytofluorimetric analyses investigating cell morphology, $\mathrm{CD} 9^{+/} \mathrm{CD}^{+}$composition and viability were performed after 3 and 7 days of incubation with the drug. Similar in vitro analyses were performed on primary cells co-cultures derived from bone marrow aspirates of ALL patients.

\section{Materials and methods}

\subsection{Reagents}

Blinatumomab (Blincyto ${ }^{\circledR}$, Amgen, Italy) was provided as a sterile $12.8 \mu \mathrm{g} / \mathrm{mL}$ infusion solution and kept at $-20{ }^{\circ} \mathrm{C}$ until use. Recombinant human interleukin-2 (IL2, I2644, Sigma-Aldrich, Italy) was suspended at a final concentration of $10 \mu \mathrm{g} / \mathrm{mL}$ in sterile phosphate-buffered saline (PBS, D8537, Sigma-Aldrich, Italy), supplemented with $0.1 \%$ human serum albumin.

\subsection{Cell cultures}

Human immortalized $\mathrm{CD}^{+} 9^{+}$leukemia cell lines, NALM6 (ACC-128) and REH (ACC-22), were purchased from DSMZ (Leipzig, Germany). Cell cultures, trypan blue exclusion assay, lysates preparation and western blot analyses are described in supplementary materials.

\subsection{Study populations}

Buffy coats of three healthy blood donors were provided by the Transfusion Service of the "Azienda Sanitaria Universitaria Giuliano Isontina" (ASUGI, Trieste, Italy). Patients were ALL children enrolled at IRCCS Burlo Garofolo in Trieste in the AIEOP-BFM ALL 2009 protocol. According to the AIEOP ALL protocol guidelines, karyotyping and cytogenetics were performed as part of the diagnostic procedures. The clinical study was approved by the local ethical committee (Protocol number CE/V 135; IRCCS Burlo Garofolo, March 5th 2012) and appropriate informed consent was obtained from patients/donors and/or their parents or guardians.

Blood samples were processed for the isolation of peripheral blood mononuclear cells (PBMC) and purification of primary T-lymphocytes $\left(\mathrm{CD}^{+}\right)$and stored at $-80^{\circ} \mathrm{C}$, as described in Supplementary material.

\subsection{Cytofluorimetric assay}

T-lymphocytes $\left(\mathrm{CD}^{+}\right)$isolated from 3 healthy donors were thawed and seeded in a 24-wells plate at $1 \times 10^{6}$ cells/ml in complete RPMI-1640 medium supplemented with IL-2 at $10 \mathrm{ng} / \mathrm{mL}$, to allow their recovery. After 24 hours (day 0), co-cultures of 5000 T-lymphocytes/well and 50,000 B-ALL cell lines (NALM6 or REH)/well were set up (seeding effector-to-target ratio $1: 10,200 \mu \mathrm{L}$ in $\mathrm{X}^{-V_{V}} \mathrm{VO}^{T M} 15$ plus $10 \mathrm{ng} / \mathrm{mL}$ IL-2 and blinatumomab $(0,1,10 \mathrm{ng} / \mathrm{mL})$. Plates were incubated at $37{ }^{\circ} \mathrm{C}(5 \%$ 
A

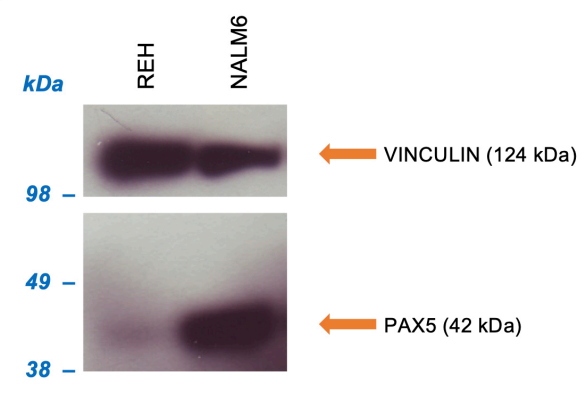

B

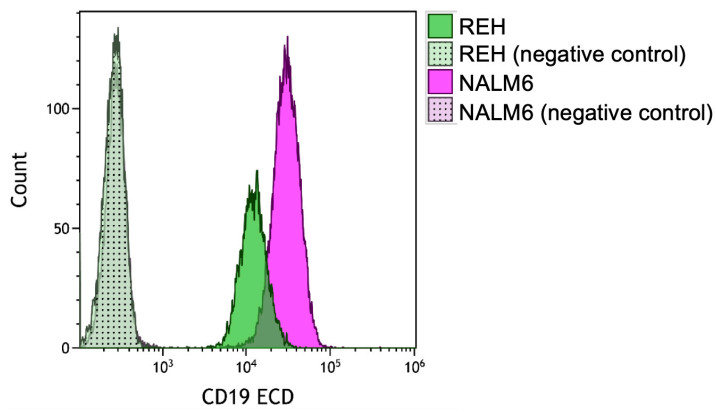

Fig. 1. PAX5 and CD19 protein expression in B-ALL cell lines, NALM6 and REH. (A) Detection of PAX5 expression in REH and NALM6 cells by western blotting; Vinculin blot used as loading control. (B) Flow cytometry analysis of CD19 expression on cell surface; $1 \times 10^{5}$ live cells were directly labelled with an anti-CD19-ECD antibody for 20 min at room temperature in the dark. X-axis represents the fluorescence intensity.

$\mathrm{CO}_{2}$ ) for 7 days; every 24 hours, $150 \mu \mathrm{L}$ of the supernatants were replaced by fresh complete culture medium \pm blinatumomab [22]. Removed supernatants were stored at $-20{ }^{\circ} \mathrm{C}$ for subsequent granzyme B (GzB) quantification. Cytofluorimetric analyses were performed on day +3 and day +7 , using 10 colors 3 lasers Navios EX (Beckman Coulter, CA, USA), acquiring at least 30,000 events for each sample. Briefly, $100 \mu \mathrm{L}$ of the cell suspensions were stained for surface antigens (CD45, CD19, CD3) and for intracytoplasmic markers (DNA and nuclei) using $20 \mu \mathrm{L}$ of a cocktail of fluorescent dyes (anti-human antibodies: antiCD45-KO, antiCD19-ECD, antiCD3-PE; 7-amino-actinomycin D (7AAD), Syto16-FITC (all from Beckman Coulter, Pasadena, CA, USA)). For each antigen, mean fluorescence intensity (MFI) was calculated using the Kaluza Analysis Software version 2.1 (Beckman Coulter, CA, USA).

The cytofluorimetric assay was also performed on patients' mononuclear cells. Due to the scarce biological material available, experiments could be performed only once per patient. Six hundred thousand cells were seeded in triplicate in X-VIVO ${ }^{T M} 15$ medium $\pm \mathrm{IL}-2(10 \mathrm{ng} / \mathrm{mL}) \pm$ blinatumomab $(0,1,10 \mathrm{ng} / \mathrm{mL})$ for 7 days. Every 24 hours, supernatants were refreshed. Cytofluorimetric analyses were performed at day +7 , according to the conditions described above.

\section{$2.5 \mathrm{GzB}$ ELISA assay}

The human GzB Platinum ELISA kit (BMS2027, Thermo Fisher Scientific, Italy) was used according to manufacturer's instructions.

\subsection{Statistical analysis}

For the cytofluorimetric assays on co-cultures including immortalized B-ALL cell lines, three independent ex- periments were performed in triplicate and data are presented as mean $\pm \mathrm{SD}$; for each patient sample, the assay was performed once, in triplicate. Data were compared by two-way ANOVA followed by Bonferroni post-test. For the GzB ELISA assay, three-way ANOVA followed by Bonferroni post-test was used. Data were analyzed by GraphPad Prism software version 8.3.0 (CA, USA) and significant differences were considered at $p$ values $<0.05$.

\section{Results}

\subsection{NALM6 and REH cells showed a differential expression of PAX5 and CD19}

According to the literature, both NALM6 and REH cell lines harbor complex karyotypes and rearrangements of chromosome 12, leading to the expression of ETV6 chimeric fusion oncoproteins (ETV6-PDGFRB in NALM6 [23] and ETV6-RUNX1 in REH [24]). Moreover, NALM6 cells harbor a focal, heterozygous deletion in the PAX5 promoter [25] and a homozygote point mutation in an intronic, non-coding poly $(\mathrm{C})$ microsatellite repeat, which is unlikely to be functional [26]. REH cells instead carry a PAX5 frameshift mutation, due to a single base insertion (C) within the coding poly $(\mathrm{C}) 7$ microsatellite repeat in exon 8 (InsP321fs). This results in premature termination of translation after amino acid 339, encoding a BSAP protein lacking the C-terminal transactivation domain [26]. To explore the relevance of these PAX5 genetic alterations in blinatumomab response, NALM6 and REH cells were employed as representative in vitro models. Differential expression of BSAP and CD19 in the two cell lines was confirmed at the protein level (Fig. 1A and Supplementary Fig. 1). Western blot results, using a commercial antibody directed against the N-terminal part of human BSAP, detected the full-length protein $(42 \mathrm{kDa})$ in NALM6, clearly expressed if compared to REH where only a faint signal appeared; no 

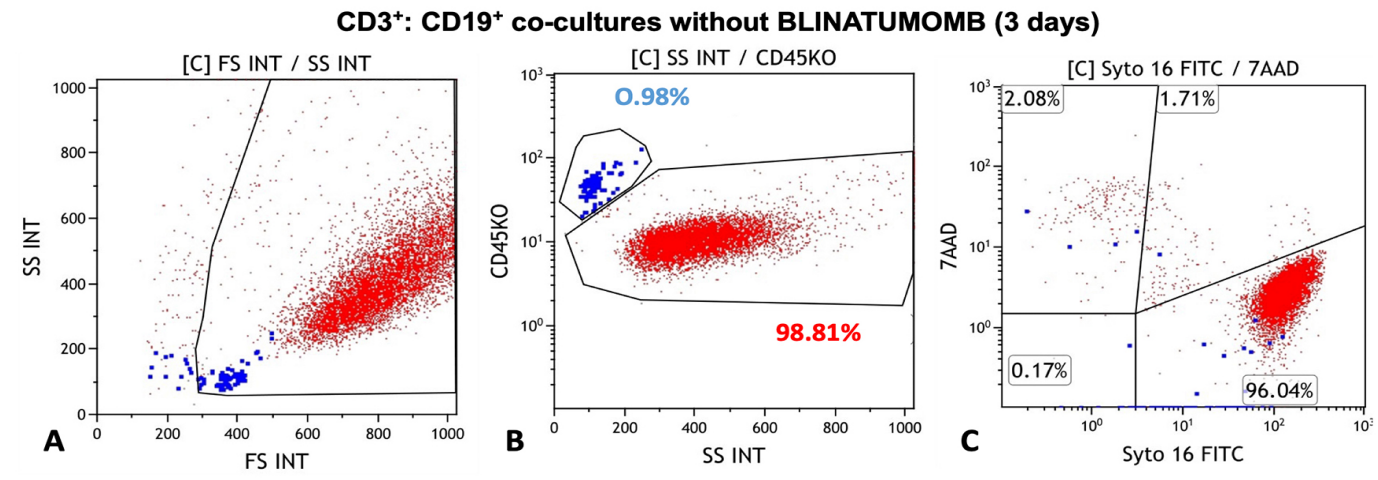

$\mathrm{CD3}^{+}$: CD19+ co-cultures $1 \mathrm{ng} / \mathrm{ml}$ BLINATUMOMB (3 days)
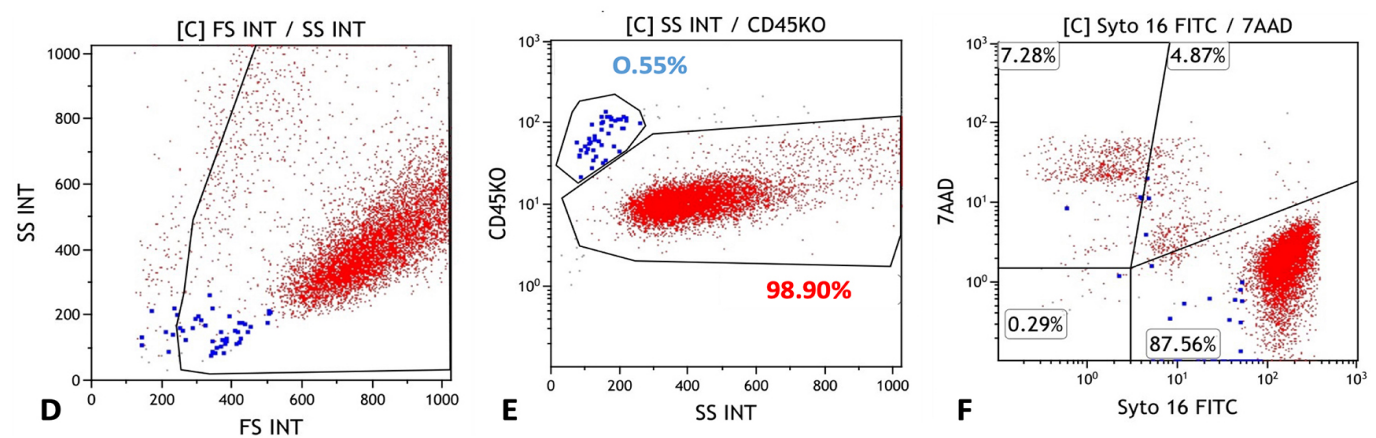

$\mathrm{CD}^{+}:$CD19+ co-cultures without BLINATUMOMB (7 days)


$\mathrm{CD3}^{+}$: CD19+ co-cultures $1 \mathrm{ng} / \mathrm{ml}$ BLINATUMOMB (7 days)
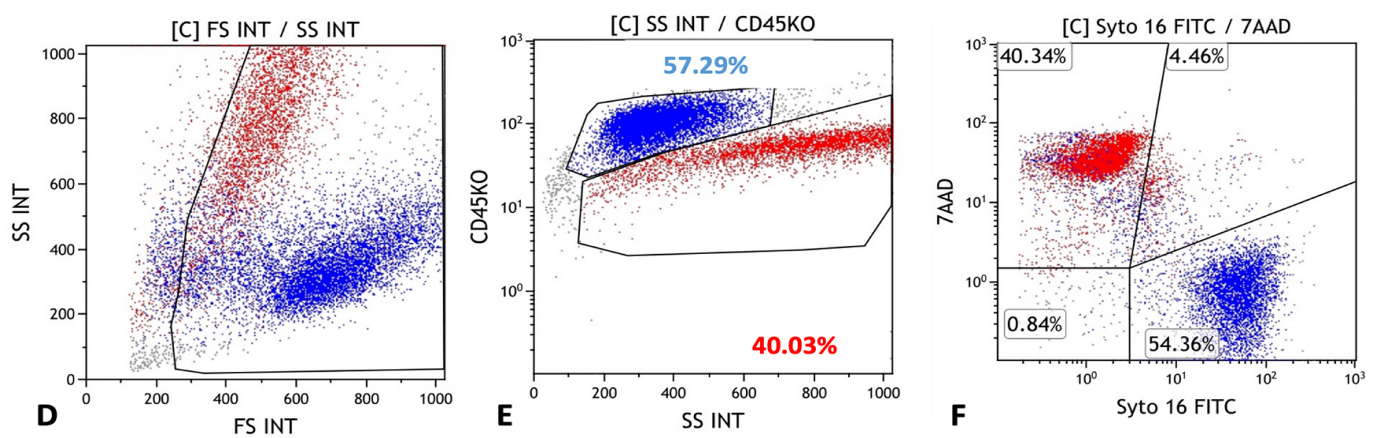

Fig. 2. Exemplificative flow cytofluorimetric analysis of the $\mathrm{CD3}^{+}$cells: $\mathrm{CD19}{ }^{+}$cells co-culture (1:10) after 3 days (upper square panel) and 7 days (lower square panel) of incubation in the absence (panels A-C) or presence of blinatumomab $1 \mathrm{ng} / \mathrm{mL}$ (panels D-F). SS/FS panels (panels A and D) and CD45/SS panels (panels B and E) are commonly acquired during diagnostic procedure in ALL, and combine cell morphological information of size and intracellular complexity (FS, SS) with labeling of a pan-leukocyte marker (CD45), distinguishing between immature lymphoblasts (larger, with a variable but moderate staining of CD45) from mature lymphocytes (smaller, with high CD45 and a near-total absence of intracellular complexity). 7-AAD/Cyto16 labelling (panels C and F) assayed cell viability. B-ALL cells are highlighted in red, healthy donors T-cells in blue. 
A) Day 3

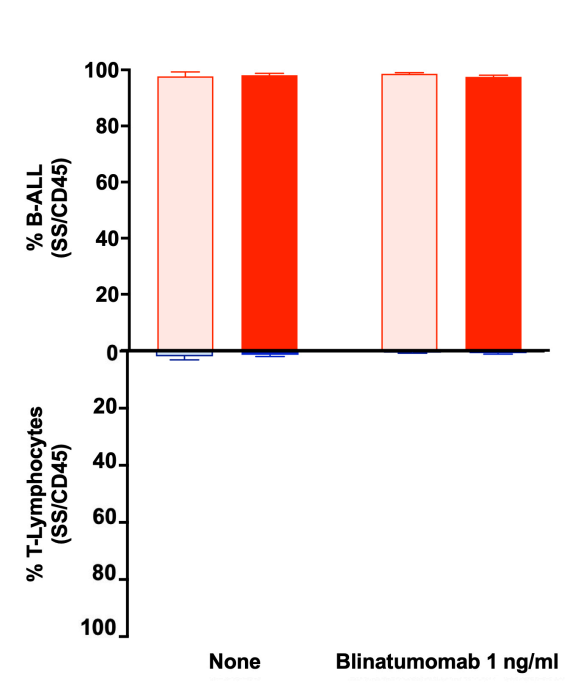

B) Day 7

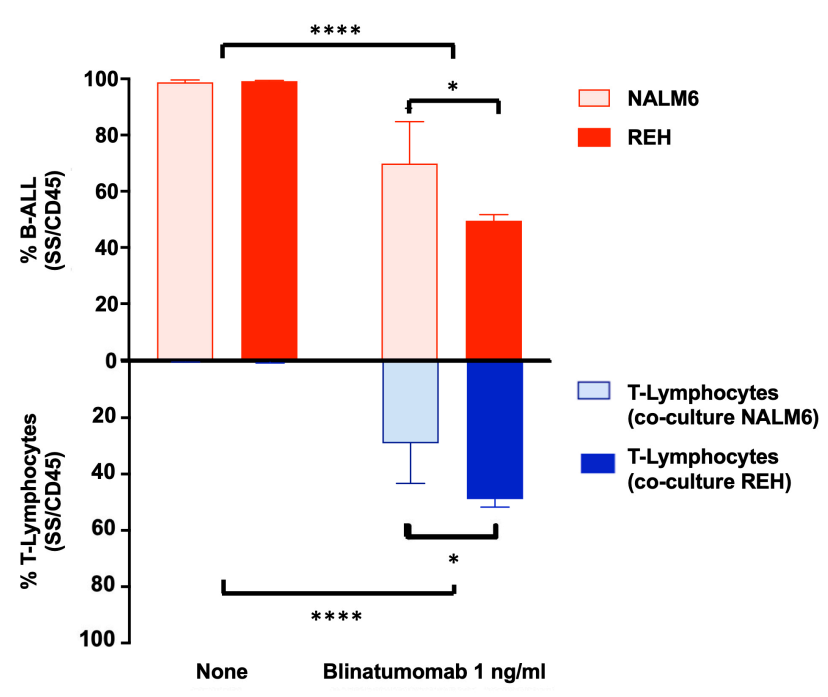

Fig. 3. Mean percentage composition of T-lymphocytes and B-ALL cell lines in the co-culture (initial effector-to-target seeding ratio, 1:10) after 3 (A) and 7 (B) days of incubation in the absence or presence of blinatumomab $1 \mathrm{ng} / \mathrm{mL}$. Error bars represent SD $(\mathrm{n}=3){ }^{*} p$-value $<0.05, * * * p$-value $<0.0001$, two-way ANOVA, Bonferroni post-test. After 3 days of incubation no difference was observed in co-cultures treated with or without blinatumomab (Panel A); after 7 days of incubation (Panel B), a significant decrease in the B-ALL cell percentage and an increase in T-lymphocytes percentage in samples treated with blinatumomab was observed.

additional truncated form of BSAP was visible (Fig. 1A). The CD19 protein surface expression on both NALM6 and REH cells was investigated by flow cytometry, staining 1 $\times 10^{5}$ cells with the anti-CD19-ECD antibody. Both cell lines, being $\mathrm{CD}^{+}{ }^{+}$, showed a fluorescence peak caused by the direct binding of the antibody to the antigen; however, a forward shift in the CD19 peak with a three times higher fluorescence intensity (median: 28895 versus 9155) in NALM6 compared to REH was observed, suggesting a higher surface density of the antigen in the former cells (Fig. 1B). PAX5 and CD19 mRNA expression levels were comparable among the two cell lines, as shown by SYBR Green qPCR (Supplementary Fig. 2).

\subsection{Co-culture of NALM6 or REH cells and T-lymphocytes respond differently to blinatumomab in vitro}

Preliminary analyses were carried out to evaluate cell survival of immortalized CD19 ${ }^{+}$B-ALL cell lines and $\mathrm{CD}^{+} \mathrm{T}$ lymphocytes in X-VIVO ${ }^{T M} 15$ cultural medium without blinatumomab. The number of cells was monitored daily over a 7 day-period by trypan blue exclusion assay (initial seeding concentration: $\mathrm{CD}^{+}$lymphocytes: 84,000 cell/mL; CD19 ${ }^{+}$cells: $62,500-500,000$ cells $/ \mathrm{mL}$ ). NALM6 or REH cells could proliferate in this serum-free medium: a seeding concentration of $250,000 \mathrm{~B}$-cells $/ \mathrm{ml}$ in 96-wells plates $(50,000$ cells/well) was chosen to guarantee a similar number of alive growing NALM6 or REH cells over one week in the untreated condition (Supplementary materials, Supplementary Fig. 3). In contrast, cell viabil- ity of T-lymphocytes was severely impaired from the first day of incubation, and survival was not increased by the addition of IL-2 in the culture medium (Supplementary Fig. 4).

To test whether the increased surface presentation of CD19 in B-cells affects blinatumomab in vitro response, co-cultures of $\mathrm{CD}^{+}$isolated lymphocytes of three different healthy donors and either NALM6 or REH cells were set up at a 1:10 ratio (initial 5000 T-cells: 50,000 B-cells). X-VIVO ${ }^{T M} 15$ medium supplemented with IL2 and fresh blinatumomab (when required) was replaced every 24 hours. Fig. 2 shows exemplificative results of the cytofluorimetric analysis performed after 3 and 7 days of incubation, respectively. Fig. 3 reports the mean percentage value $( \pm \mathrm{SD})$ of B-ALL cells and T-lymphocytes, as measured by the SS/CD45 analysis. After 3 days of incubation, there was no difference between the condition with or without blinatumomab in the co-cultured Band T-cells (Fig. 3A). Changes were on the contrary observed after 7 days (Fig. 3B), with a significant decrease in the B-ALL cell percentage in treated compared to untreated samples (two-way ANOVA, Bonferroni post-test, $p$ $<0.0001)$; the decrease was particularly evident in REH compared to NALM6 after drug exposure (ANOVA twoway, Bonferroni post-test, $p<0.05$ ). At the same time point, treatment with blinatumomab $1 \mathrm{ng} / \mathrm{mL}$ significantly increased T-lymphocytes in comparison to controls (twoway ANOVA, Bonferroni post-test, $p<0.0001$ ), with a more important effect for T-lymphocytes in co-culture with 



Fig. 4. Mean percentage value of T-lymphocytes viability and B-ALL cell lines mortality in the co-culture (initial effector-totarget seeding ratio, 1:10) after 3 (A) and (7) days of incubation in the absence or presence of blinatumomab $1 \mathrm{ng} / \mathrm{mL}$. Error bars represent $\mathrm{SD}(\mathrm{n}=3)$. $* p$-value $<0.05,{ }^{* * *} p$-value $<0.001, * * * * p$-value $<0.0001$ two-way ANOVA, Bonferroni post-test. A significant increase in mortality of both leukemic cell lines is observed after incubation with blinatumomab $1 \mathrm{ng} / \mathrm{mL}$ in comparison to untreated cells at both time points. Mortality in cells treated with blinatumomab is higher in REH compared to NALM6 at day +3 (Panel A) and is almost complete in both cell lines at day +7 (Panel B). No effect on T-lymphocytes viability was observed.

REH than with NALM6 (two-way ANOVA, Bonferroni post-test, $p<0.05$ ).

7AAD and Syto16 labelling were used to analyze cell viability; Fig. 4 reports the percentage value of dead NALM6 or REH $\left(\mathrm{CD} 19^{+}, 7 \mathrm{AAD}^{+}\right)$and of alive cocultured T-cells $\left(\mathrm{CD}^{+}, 7 \mathrm{AAD}^{-} /\right.$Syto $\left.16^{+}\right)$, measured in flow cytometry. A significant increase in mortality of both leukemic cell lines was observed after incubation with blinatumomab $1 \mathrm{ng} / \mathrm{mL}$ in comparison to untreated cells at both time points (untreated versus treated, day $+3, p$ value $<0.001$, Fig. $4 \mathrm{~A}$; day $+7, p$-value $<0.0001$, twoway ANOVA, Bonferroni post-test, Fig. 4B). Mortality in cells treated with blinatumomab was higher in REH compared to NALM6 at day $+3(44.46 \pm 6.9 \%$ versus $25.54 \pm$ $12.9 \%$, respectively, two-way ANOVA, Bonferroni posttest, $p<0.05$, Fig. $4 \mathrm{~A}$ ) and was almost complete in both cell lines at day +7 (REH: $95.12 \pm 2.1 \%$ NALM6: 97.17 $\pm 1.8 \%$ ). Statistical analyses did not show any difference in T-lymphocytes survival neither comparing those exposed to blinatumomab to the unexposed ones at both 3 and 7 days (percentage of alive cells $>80 \%$ ), nor comparing Tlymphocytes co-cultured with NALM6 to those co-cultured with REH cells (Fig. 4).

\subsection{Co-culture of NALM6 or REH and T-lymphocytes} show a different blinatumomab induced $\mathrm{GzB}$ daily release over time

$\mathrm{GzB}$ is a mammalian aspartic acid-cleaving serine protease, released by cytotoxic T lymphocytes. GzB was measured by an ELISA assay in supernatants collected every 24 hours, as a measure of daily T-lymphocytes activation. Data are shown in Table 1 and Supplementary Fig. 5. In the untreated condition, GzB levels were low, although constantly growing over time, likely because of an intrinsic drugindependent mechanism of T-lymphocyte activation; levels were comparable over time between co-cultures including either NALM6 or REH. Blinatumomab enhanced the daily release of GzB compared to untreated controls at any time point and regardless of the B-ALL cell line present in the co-culture ( $p$-value $<0.0001$, three-way ANOVA). Concentrations of GzB reached the maximum $(3478.1 \mathrm{pg} / \mathrm{mL})$ already at day +3 in NALM6 co-culture, and were significantly lower in REH co-cultures at days +3 and +4 ( $p$ value $<0.0001$, three-way ANOVA), reaching a comparable plateau only at day +5 . In REH co-cultures, the 24hours release of $\mathrm{GzB}$ was almost doubling between days +3 and +4 and days +4 and +5 . 
Table 1. GzB daily release in $\mathrm{CD3}^{+}: \mathrm{CD}^{+}{ }^{+}$co-cultures (initial effector-to-target seeding ratio, 1:10).

\begin{tabular}{|c|c|c|c|c|c|c|c|c|}
\hline \multirow{4}{*}{ Days } & \multicolumn{3}{|c|}{ NALM6 co-culture } & \multicolumn{3}{|c|}{ REH co-culture } & \multirow{4}{*}{$p^{\dagger}$} & \multirow{4}{*}{$p \ddagger$} \\
\hline & & $\mathrm{zB}(\mathrm{pg} / \mathrm{mL})$ & & & $\mathrm{GzB}(\mathrm{pg} / \mathrm{mL})$ & & & \\
\hline & \multirow{2}{*}{ Untreated } & Blinatumomab & \multirow{2}{*}{$p^{*}$} & \multirow{2}{*}{ Untreated } & Blinatumomab & \multirow{2}{*}{$p^{*}$} & & \\
\hline & & $1 \mathrm{ng} / \mathrm{mL}$ & & & $1 \mathrm{ng} / \mathrm{mL}$ & & & \\
\hline+3 & $37.2 \pm 19.2$ & $>3478.1$ & $<0.0001$ & $9.4 \pm 4.6$ & $1073.0 \pm 29.5$ & $<0.0001$ & Ns & $<0.0001$ \\
\hline+4 & $100.6 \pm 66.5$ & $>3478.1$ & $<0.0001$ & $28.2 \pm 11.2$ & $2091 \pm 216.0$ & $<0.0001$ & Ns & $<0.0001$ \\
\hline+5 & $249.5 \pm 149.4$ & $>3478.1$ & $<0.0001$ & $205.6 \pm 111.5$ & $>3478.1$ & $<0.0001$ & Ns & Ns \\
\hline+6 & $288.1 \pm 295.6$ & $>3478.1$ & $<0.0001$ & $725.2 \pm 636.4$ & $>3478.1$ & $<0.0001$ & Ns & Ns \\
\hline+7 & $648.5 \pm 376.1$ & $>3478.1$ & $<0.0001$ & $696.7 \pm 201.7$ & $>3478.1$ & $<0.0001$ & Ns & Ns \\
\hline
\end{tabular}

Mean values $\pm \mathrm{SD}(\mathrm{n}=3)$ are reported. $p$-value calculated according to three-way ANOVA: * basal (untreated) versus blinatumomab $(1 \mathrm{ng} / \mathrm{mL})$ GzB induced release in NALM6 and REH co-cultures, $\uparrow$ basal GzB release comparison between NALM6 and REH co-cultures, $\$$ blinatumomab $(1 \mathrm{ng} / \mathrm{mL})$ GzB induced release comparison between NALM6 and REH co-cultures. GzB, granzyme-B; Ns, not significant.

Table 2. Patients' demographic characteristics and $\mathrm{CD3}^{+} / \mathrm{CD}^{+} 9^{+}$cells in the diagnostic bone marrow.

\begin{tabular}{|c|c|c|c|c|c|c|c|c|c|}
\hline \multirow{2}{*}{ Patients } & \multirow{2}{*}{ Age } & \multirow{2}{*}{ Gender } & \multirow{2}{*}{ Diagnosis } & \multirow{2}{*}{ Genetic alterations } & \multirow{2}{*}{ Immunophenotype } & \multirow{2}{*}{$\begin{array}{l}\mathrm{CD} 19^{+} \mathrm{imm}- \\
\text { ature cells }(\%)\end{array}$} & \multicolumn{2}{|c|}{ Mature cells } & \multirow{2}{*}{$\begin{array}{l}\text { Effector-to } \\
\text { target ratio }\end{array}$} \\
\hline & & & & & & & $\mathrm{CD}^{+}(\%)$ & $\mathrm{CD} 19^{+}(\%)$ & \\
\hline$\# 1$ & 14.6 & M & 2nd RELAPSE & None & ALL-B COMMON & 66 & 6.2 & 2.8 & $1: 11$ \\
\hline$\# 2$ & 7.9 & M & 1st ONSET & MLL/AF4 & ALL-B COMMON & 86 & 3 & 0.4 & $1: 30$ \\
\hline$\# 3$ & 7.0 & $\mathrm{~F}$ & 1st ONSET & None & ALL-B COMMON & 82 & 10.7 & 1.6 & $1: 8$ \\
\hline$\# 4$ & 10.7 & $\mathrm{~F}$ & 1st ONSET & None & NA & 95 & 1.4 & 0.3 & $1: 68$ \\
\hline$\# 5$ & 11.3 & M & 1st ONSET & None & ALL pre-B & 93 & 2 & 0.7 & $1: 47$ \\
\hline
\end{tabular}

\subsection{Patient primary co-cultures of B-ALL lymphoblasts} and T-lymphocytes respond differently to blinatumomab in vitro

Blinatumomab in vitro assay was performed on primary mononuclear cells co-cultures of 8 patients with Philadelphia-negative B-ALL; results are available only for 5 children (median (IQ) age: 10.7 (7.9-11.3) years; males: $60 \%)$ : in the other 3 , the assay could not be concluded due to technical reasons. $\mathrm{CD}^{+}$lymphocytes and primary $\mathrm{CD} 9^{+}$leukemic cells were derived from bone marrow aspirates collected at diagnosis: percentages of immature CD19 ${ }^{+}$B-cells exceeded $66 \%$ in the diagnostic samples (mean $\pm \mathrm{SD}: 84.40 \pm 11.55 \%$ ) whereas mature CD19 ${ }^{+} \mathrm{B}-$ lymphocytes and $\mathrm{CD}^{+} \mathrm{T}$-lymphocytes were $1.15 \pm 1.04 \%$ and $4.65 \pm 3.84 \%$, respectively; the $\mathrm{CD}^{+}: \mathrm{CD}^{+} 9^{+}$cells ratio was at least equal to $1: 8$ (Table 2). Blasts $P A X 5$ genetic status was not known.

Fig. 5 reports the mean percentage value $( \pm$ SD) of blast cytotoxicity and T-lymphocytes activation after 7 days of in vitro incubation, measured by the $\mathrm{CD} 19^{+}$gated $7 \mathrm{AAD}^{+}$and by the $\mathrm{CD}^{+}$gated $\mathrm{SS} / \mathrm{CD} 45$ cytofluorimetric panels, respectively. Under basal condition, blasts cytotoxicity was highly variable among samples (two-way ANOVA, Bonferroni post-test, $p<0.001$ for untreated $\mathrm{CD} 19^{+}$cells) and was not affected by the addition of IL- 2 in the cultural medium. In contrast, comparable levels of alive T-lymphocytes were observed and were slightly enhanced by the presence of the cytokine $\left(\mathrm{CD}^{+}\right.$cells: mean percentage value $( \pm \mathrm{SD}): 2.97(1.11-3.27) \%$ and $1.80(1.74$ $2.60) \%$ with and without IL-2 respectively; $p<0.0001)$. A positive in vitro pharmacological response to blinatumomab was defined as a simultaneous significant increase in blast mortality and T-lymphocytes activation induced by the drug, whereas non-simultaneous or failed enhancements were considered as resistance. In the IL-2 free condition, only two samples responded properly to blinatumomab ( $p$ $<0.0001$ for both $\mathrm{CD}_{19}{ }^{+}$and $\mathrm{CD}^{+}$cells), although at different drug concentrations ( $\mathrm{pt} \# 1$ at $10 \mathrm{ng} / \mathrm{mL}, \mathrm{pt} \# 2$ at 1 $\mathrm{ng} / \mathrm{mL}$ ). Blinatumomab failed to induce any effect in samples derived from $\mathrm{pt} \# 3$, pt\#4 and $\mathrm{pt} \# 5$. The presence of IL-2 in the cultural medium induced a significant increase in Tlymphocytes compared to basal condition in four out of five patients (all but pt\#5). The lower concentration of blinatumomab was thus sufficient to induce a response in $\mathrm{pt} \# 1$ ( $p$ $<0.0001$ for both $\mathrm{CD}_{19}{ }^{+}$and $\mathrm{CD}^{+}$cells). In $\mathrm{pt} \# 3, \mathrm{CD}^{+}$ cells switched significantly from $3.27 \%$ to $17.42 \%$ in drugfree and blinatumomab-treated samples $(p<0.0001)$ and in pt\#4 from $0.41 \%$ to $10.03 \%$ ( $p<0.0001)$, however, in both cases without effect on blasts mortality (pt\#3: from $8.02 \%$ to $14.16 \%, p>0.05$; $\mathrm{pt} \# 4$ : from $5.05 \%$ to $9.07 \%$ respectively, $p>0.05)$. Interestingly, $\mathrm{pt} \# 5$ remained resistant and did not show any change compared to IL-2 free condition. These in vitro results are unrelated to the percentages of immature $\mathrm{CD} 19^{+}$B-cells present in the diagnostic samples. 


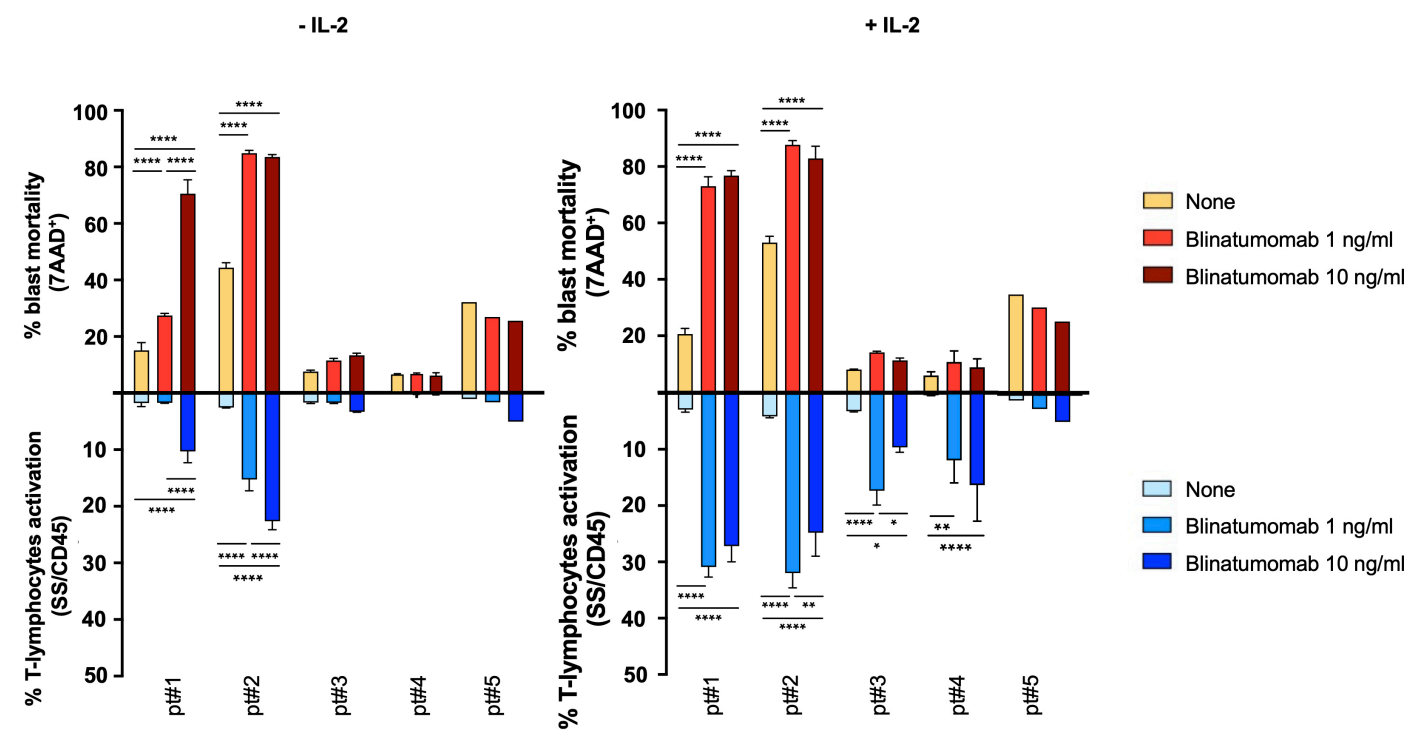

Fig. 5. Blinatumomab in vitro cytofluorimetric assay on patients' samples. Mean percentage value (+SD) of patients blasts mortality (gate $\mathrm{CD} 19^{+}, 7 \mathrm{AAD}^{+}$, in red) and T-lymphocytes activation (gate $\mathrm{CD}^{+}, \mathrm{SS} / \mathrm{CD} 45$, in blue) after 7 days of incubation (initial seeding 600,000 cells/well). ${ }^{*} p$-value $<0.05, * * p$-value $<0.01, * * * *, p$-value $<0.0001$, two-way ANOVA, Bonferroni post-test.

\section{Discussion}

Blinatumomab is a promising agent for both firstonset and relapsed/refractory ALL, however, primary and secondary resistance occurs, and still needs to be characterized. Current recruiting clinical trials investigate on blinatumomab effectiveness in comparison to standard therapeutic procedures (e.g., AIEOP-BFM ALL 2017 protocol, NCT03643276) and/or on the proportion of patients with blinatumomab poor-response as primary outcomes. Pharmacogenetic traits or B-lymphoblasts genetics could modulate treatment efficacy or predispose to treatment failure. Only few reports on a very limited number of patients suggest that blinatumomab could be a valid therapeutic approach for specific ALL genetic subtypes. Zhao and coworkers [27] showed that the activation of JAKSTAT signaling in leukemic cells of 44 patients harboring high-risk CRLF2 and EPOR-rearrangements is an important determinant of blinatumomab response. Mouttet and collaborators [28] reported durable remissions after blinatumomab treatment in 9 patients with a rare subtype of ALL with a dismal outcome, characterized by high and homogeneous expression of CD19 on blast cells and by the presence of the $\mathrm{t}(17 ; 19)$ (q21-q22;p13), leading to the TCF3-HLF fusion gene. Moreover, Zhao and collaborators [29] observed, in 44 adults with relapsed or refractory B-ALL treated with blinatumomab, that multiple mechanisms may contribute to CD19 loss and relapse, including CD19 mutations, CD19 mutant allele-specific expression, $C D 19$ low RNA expression and also mutations in the member of the CD19 signaling complex CD81. This underlines the importance of possible variations in CD19, including PAX5, in relation to treatment response [29]. Iden- tifying patients' prognostic biomarkers and/or finding a reliable predictive in vitro sensitivity assay could be crucial for an effective proactive management of blinatumomab, especially considering the high costs, the length of treatment ( 2 cycles of 28 days continuous infusion), its toxicity [30] and current percentages of failure (20-30\% patients with relapse/refractory ALL) associated with blinatumomab therapy. Another CD19-targeted immunotherapy, patient-specific chimeric antigen receptor $\mathrm{T}$ cell therapy (CAR-T), was recently introduced in the clinics with encouraging and impressive response rates in the cure of relapsed/refractory ALL and other hematological diseases. The choice between CAR-T and BiTE immunotherapy depends on several clinical features that may affect efficacy, including relative disease burden, antigen expression, and T-cell function, as well as patient and disease characteristics. Adverse effects of CD19-targeted immunotherapies, such as cytokine release syndrome and neurotoxicity, still need to be reduced: these events may be more frequent and severe in patients receiving CAR-T [31,32]. Blinatumomab has the advantage to use the same standard drug for every person treated and therapy-associated costs may be lower. Ongoing attempts in CAR-T aim to develop offthe-shelf CAR T-cell therapies that should be immediately available for use without being manufactured for each patient. First attempts used CRISPR/Cas9-engineered universal CD19/CD22 CAR-T cells to avoid host immunemediated rejection when infused in patients, showing a manageable safety profile and prominent antileukemic activity [33].

In this study, a cytofluorimetric approach was used to measure in vitro blinatumomab effects on co-cultures 
of immortalized $\mathrm{CD} 19^{+}$B-ALL cells and primary $\mathrm{CD}^{+}$ T-lymphocytes, to investigate whether the drug response could be affected by the CD19 surface expression levels determined by the PAX5 genetic status of leukemic cells. The different expression of BSAP and CD19 in the immortalized cell lines NALM6 and REH was confirmed at the protein level. Western blot analysis revealed the presence of the full-length BSAP in NALM6, whereas only a faint signal appeared in REH cells. Analysis of mRNA expression levels confirmed previous data of Best and coworkers, who showed comparable PAX5 mRNA levels between these two cell lines [26]. Thus the lower BSAP levels could be ascribable to the PAX5 frameshift (fs) somatic mutation (P321fs) harbored by REH, affecting mRNA translation or protein stability. PAX5 fs mutations occurred in $\sim 2 \%$ of ALL patients, as demonstrated by $\mathrm{Gu}$ and co-workers using integrated genomic analysis of 1,988 childhood and adult cases; $\sim 40 \%$ of the PAX5 fs mutations observed lead to truncated BSAP proteins, similar to what is observed in REH cells, thus confirming this cell line as a useful cellular model [25]. The lack of the C-terminal transactivation domain functionally impaired BSAP, and the truncated protein failed to fully-activate BSAP-dependent gene transcription $[34,35]$. Indeed, a three times lower mean fluorescence intensity for CD19 was observed in REH compared to NALM6 cells, as previously reported by Haso and collaborators [36]. Indeed, these authors calculated the surface antigen density on different B-ALL cell lines, finding that the average number of CD19 molecules per cell in REH was 15,000 versus 55,000 in NALM6 [36]. Preliminary analyses were carried out to evaluate the reliability of the experimental condition used for the in vitro blinatumomab assay. The effector-to-target ratio (1:10), with exceeding B-precursor cells, was chosen to resemble the invasion of leukemic blasts in the bone marrow, a condition where a primary resistance to blinatumomab could result in a dismal outcome for relapsed/refractory CD19+ ${ }^{+}$ALL patients [6,29,37-39]. Besides being administered at relapse, the role of blinatumomab in at risk patients is now under investigation (e.g., AIEOP-BFM ALL 2017 protocol). In this paper, we have investigated only the 1:10 ratio, but other effector-to target ratio should be used in further studies for a complete overview on blinatumomab in vitro effects. Blinatumomab was refreshed on a daily basis, mimicking more closely drug exposure in patients. Indeed, due to its short half-life (mean \pm standard deviation: $2.11 \pm 1.42$ hours in adults) [40], the drug is administered by continuous infusion in cycles of 4 weeks. The blinatumomab concentration used $(1 \mathrm{ng} / \mathrm{mL})$ was in line with steady state concentration values measured in adult ALL patients during the second cycle of blinatumomab [41]. The cytofluorimetric assay allowed to appreciate both blinatumomab-induced effects, i.e., the decreased percentage of B-ALL immortalized cells combined to the T-lymphocytes increase and activation, at day +7 . However, at this time point, the drug ef- fects were already accomplished since $\mathrm{CD} 19^{+}$cell mortality was almost complete ( $>95 \%$ ), suggesting that the ideal timing for investigating simultaneously both drug effects should fall between days +3 and +7 . Interestingly, CD19 ${ }^{+}$ cell death was already observed at day +3 in blinatumomabtreated samples, with a more pronounced effect in REH than NALM6, contrary to what could be expected considering the reduced amount of $\mathrm{GzB}$ released in the co-culture supernatants and the lack of $\mathrm{CD}^{+}$activation at this early time point. Several hypotheses could be postulated to explain such results. It is known that REH cells are more sensitive than NALM6 to conventional ALL chemotherapy [42], in agreement to what is observed in ETV6-RUNX1 ALL patients who have good prognostic parameters and a favorable outcome and in ETV6-PDGFRB patients who failed to reach remission $[43,44]$. In this report, we showed for the first time the different response of these B-ALL cell lines to the novel immunomodulatory agent blinatumomab. One hypothesis is that the lower $\mathrm{CD} 19^{+}$expressing REH cells could be more sensitive to cytotoxic stimuli than NALM6 because, in the balance between cell survival and apoptotic signals, they could be more susceptible to pro-apoptotic signals induced by the drug. Indeed, cell surface dynamic analysis revealed that CD19 and BCR come together on plasma membrane microclusters, and that CD19-defective B-cells show a reduced microcluster formation and initiation of BCR-dependent signaling, thus affecting the survival pathway [45]. As a second hypothesis, it could not be ruled out that NALM6 and REH have a different GzB susceptibility, since GzB-mediated cell death is largely dependent on a pathway that is regulated by the antiapoptotic protein $\mathrm{Bcl}-2$, another target gene of BSAP, which is less expressed in BSAP-deficient cells compared to wild type cells $[46,47]$. In our experiments we did not assess whether NALM6 and REH stimulate T-cell subpopulations $\left(\mathrm{CD} 8^{+}\right.$effector memory T-cells and $\mathrm{CD} 4^{+}$regulatory $\mathrm{T}$ cells (Tregs)), differently. $\mathrm{CD} 8^{+}$cells showed a greater and faster blinatumomab-induced cytotoxic capability than other activated cells, with specific production of cytotoxic factors and cytokines [48]. A higher percentage of Tregs were associated with unfavorable outcomes in adult B-ALL patients treated with blinatumomab [49]. This occurred likely because activated Tregs lead to IL10 production, resulting in suppression of T-cell proliferation and in a reduction of the $\mathrm{CD}^{+}$-mediated lysis of ALL cells [50,51]. Duell and collaborators demonstrated that CD19+ B-ALL blasts and NALM6 cells induced Treg activation to the same degree [49]. In a recent analysis at single cell transcriptome resolution, a target cell-dependent mechanism of T-cell activation by blinatumomab, mediated by the cytokine TNFSF4, was observed [52]. Whether $\mathrm{CD}^{+} /$ $\mathrm{CD}^{+}$ratio (and IL-10 or TNFSF4 levels) change between NALM-6 and REH co-cultures was not established in our experiments. Finally, upregulation of inhibitory immune checkpoints, mainly PD-L1, has been recognized as a ma- 
jor mechanism of resistance to BiTE therapy [53], being increased in relapsed ALL patients and after BiTE treatment in ALLs refractory to blinatumomab [54]. Future studies could consider PD-L1 surface expression in NALM6 and REH co-cultures to investigate its contribution to the different reaction to the drug. All together, these observations suggest that an in-depth analysis of other activation/inhibitory markers involved in blinatumomab in vitro susceptibility are needed.

$\mathrm{CD} 19^{+}$loss is one of the most significant escape mechanisms of B-ALL blasts after blinatumomab therapy [55]; however, CD19 negative relapses still represent a minority of cases, being reported only in $1 / 3$ of patients [5659]. Blinatumomab is given to CD19+ B-ALL patients, but there are not studies investigating the impact of blasts $\mathrm{CD}_{1} 9^{+}$antigen initial load on treatment success or as determinant of CD19-positive versus CD19-negative relapses after drug exposure. In patients treated with tisagenlecleucel (a CD19-specific CAR-T), low tumor burden is a factor associated with CD19-positive relapses, in contrast to the high burden associated to CD19-negative ones. It was hypothesized that high amount of CD19 target (i.e., high tumor burden) could be involved in CAR-T- persistence, with the drawback of an increased risk of CD19 negative clones selection, able to escape CAR-T immunosurveillance [60]. For other well-established biological drugs such as trastuzumab, specifically used for HER2 receptor positive cancers, therapeutic failure could occur in the presence of high HER2 expression, and different response rates were observed among subsets of HER2-positive patients [61]. All together, these evidences suggest that the presence of the molecular target drives the choice of the biological drug to be used, but a complex and non linear correlation between the target expression levels and the effective therapeutic response takes place, particularly for biological therapies that activate immune cells [5]. Indeed, the therapeutic response is a multifactorial event that could involve several pathways.

Measurement of the in vitro effects of blinatumomab on primary mononuclear cells without purification of $\mathrm{CD} 19^{+}$or $\mathrm{CD}^{+}$cells were performed to assess the assay feasibility on biological material derived from patients' bone marrows. Only a single time point measurement was possible due to the scarce number of alive primary cells recovered after diagnostic procedures and mononuclear cells isolation; moreover, survival of untreated cells was compromised over the 7 days of incubation in $\sim 40 \%$ of the cases. Besides these technical limitations, the assay showed a variability in the blinatumomab in vitro response, and identified co-cultures of patients' primary cells non-responsive to the BiTE antibody. The blinatumomab in vitro cytofluorimetric assay could be used to screen the in vivo patients' drug response, if its predictive power will be proven; however, this purpose goes beyond the aim of this paper. Because none of the patients of this study underwent blinatumomab therapy, a preliminary correlation analysis between cytofluorimetric in vitro results and in vivo pharmacological response could not be performed.

\section{Conclusions}

Results presented in this study are preliminary and far from being exhaustive. However, the in vitro cytofluorimetric assay here proposed is suitable for studying the blinatumomab response in $\mathrm{CD}^{+}: \mathrm{CD} 19^{+}$cell co-cultures, simulating the condition of lymphoblasts invasion in the bone marrow. Nonetheless, optimization of the assay is still required, particularly to find out the ideal time of observation. Screening of a larger panel of B-ALL cell line models (particularly focusing on those with hyper-activated JAK/STAT pathway and/or $\mathrm{t}(17 ; 19)$ rearrangement) or engineered cells to modulate $P A X 5$ and/or CD19 expression, would help to better understand the hypothesis-driven question relative to $P A X 5$ or other B-cells genetic abnormalities contribution in drug response [62,63]. The in vitro assay here proposed could represent a model for better understanding the complex biology of blinatumomab response.

\section{Abbreviations}

ALL, Acute lymphoblastic leukemia; BiTE, bispecific T-cell engager; BSAP, B-cell lineage specific activator protein; GzB, granzyme B; IL-2, recombinant human interleukin-2; PBMC, peripheral blood mononuclear cells; PBS, phosphate-buffered saline; Treg, regulatory T cell.

\section{Author contributions}

Conceptualization-RF, MG, GS and GD; Data curation-SB, MG and RF; Formal analysis-SB and RF; Funding acquisition-GD; Investigation- $\mathrm{SB}, \mathrm{MG}, \mathrm{EP}$; Writing - original draft—SB and RF; Writing - review \& editing-MR, AT, GD and GS.

\section{Ethics approval and consent to participate}

The study was conducted according to the guidelines of the Declaration of Helsinki, and approved by the Institutional Review Board (or Ethics Committee) of I.R.C.C.S. Burlo Garofolo (Protocol number CE/V 135; March 5th 2012). Informed consent was obtained from all subjects involved in the study.

\section{Acknowledgment}

The authors gratefully acknowledge the support of Institute for Maternal \& Child Health (I.R.C.C.S) "Burlo Garofolo", Trieste.

\section{Funding}

This work was supported by the Institute for Maternal and Child Health (I.R.C.C.S) "Burlo Garofolo," Trieste, Italy (grant number RC 05/2012). 


\section{Conflict of interest}

The authors declare no conflict of interest.

\section{Supplementary material}

Supplementary material associated with this article can be found, in the online version, at https://www.imrpre ss.com/journal/FBL/27/2/10.31083/j.fb12702039.

\section{References}

[1] Franca R, Rebora P, Bertorello N, Fagioli F, Conter V, Biondi A, et al. Pharmacogenetics and induction/consolidation therapy toxicities in acute lymphoblastic leukemia patients treated with AIEOP-BFM all 2000 protocol. The Pharmacogenomics Journal. 2017; 17: 4-10.

[2] AIRTUM Working Group; CCM; AIEOP Working Group. Italian cancer figures, report 2012: Cancer in children and adolescents. Journal of Preventive Epidemiology. 2013; 37: 1-225.

[3] Pui C, Yang JJ, Hunger SP, Pieters R, Schrappe M, Biondi A, et al. Childhood Acute Lymphoblastic Leukemia: Progress through Collaboration. Journal of Clinical Oncology. 2015; 33 : 2938-2948.

[4] Conter V, Aricò M, Basso G, Biondi A, Barisone E, Messina $\mathrm{C}$, et al. Long-term results of the Italian Association of Pediatric Hematology and Oncology (AIEOP) Studies 82, 87, 88, 91 and 95 for childhood acute lymphoblastic leukemia. Leukemia. 2010; 24: 255-264.

[5] Franca R, Favretto D, Granzotto M, Decorti G, Rabusin M, Stocco G. Epratuzumab and Blinatumomab as Therapeutic Antibodies for Treatment of Pediatric Acute Lymphoblastic Leukemia: Current Status and Future Perspectives. Current Medicinal Chemistry. 2017; 24

[6] Topp MS, Gökbuget N, Stein AS, Zugmaier G, O’Brien S, Bargou RC, et al. Safety and activity of blinatumomab for adult patients with relapsed or refractory B-precursor acute lymphoblastic leukaemia: a multicentre, single-arm, phase 2 study. The Lancet Oncology. 2015; 16: 57-66.

[7] Lee KJ, Chow V, Weissman A, Tulpule S, Aldoss I, Akhtari M. Clinical use of blinatumomab for B-cell acute lymphoblastic leukemia in adults. Therapeutics and Clinical Risk Management. 2016; 12: 1301-1310.

[8] Nagorsen D, Baeuerle PA. Immunomodulatory therapy of cancer with T cell-engaging BiTE antibody blinatumomab. Experimental Cell Research. 2011; 317: 1255-1260.

[9] Brown PA, Ji L, Xu X, Devidas M, Hogan LE, Borowitz MJ, et al. Effect of Postreinduction Therapy Consolidation with Blinatumomab vs Chemotherapy on Disease-Free Survival in Children, Adolescents, and Young Adults with first Relapse of BCell Acute Lymphoblastic Leukemia. The Journal of the American Medical Association. 2021; 325: 833.

[10] Locatelli F, Zugmaier G, Rizzari C, Morris JD, Gruhn B, Klingebiel T, et al. Effect of Blinatumomab vs Chemotherapy on Event-Free Survival among Children with High-risk firstRelapse B-Cell Acute Lymphoblastic Leukemia. The Journal of the American Medical Association. 2021; 325: 843.

[11] Jabbour E, Düll J, Yilmaz M, Khoury JD, Ravandi F, Jain N, et al. Outcome of patients with relapsed/refractory acute lymphoblastic leukemia after blinatumomab failure: No change in the level of CD19 expression. American Journal of Hematology. 2018; 93: 371-374.

[12] Ruella M, Maus MV. Catch me if you can: Leukemia Escape after CD19-Directed T Cell Immunotherapies. Computational and Structural Biotechnology Journal. 2016; 14: 357-362.

[13] Fujimoto M, Fujimoto Y, Poe JC, Jansen PJ, Lowell CA, DeFranco AL, et al. CD19 Regulates Src Family Protein Tyrosine
Kinase Activation in B Lymphocytes through Processive Amplification. Immunity. 2000; 13: 47-57.

[14] Otero DC, Omori SA, Rickert RC. CD19-dependent Activation of Akt Kinase in B-lymphocytes. Journal of Biological Chemistry. 2001; 276: 1474-1478.

[15] Kozmik Z, Wang S, Dörfler P, Adams B, Busslinger M. The promoter of the CD19 gene is a target for the B-cell-specific transcription factor BSAP. Molecular and Cellular Biology. 1992; 12: 2662-2672.

[16] Busslinger M. Transcriptional Control of Early B Cell Development. Annual Review of Immunology. 2004; 22: 55-79.

[17] Matthias P, Rolink AG. Transcriptional networks in developing and mature B cells. Nature Reviews Immunology. 2005; 5: 497508.

[18] Nebral K, Denk D, Attarbaschi A, König M, Mann G, Haas OA, et al. Incidence and diversity of PAX5 fusion genes in childhood acute lymphoblastic leukemia. Leukemia. 2009; 23: 134-143.

[19] Mullighan CG, Goorha S, Radtke I, Miller CB, Coustan-Smith $\mathrm{E}$, Dalton JD, et al. Genome-wide analysis of genetic alterations in acute lymphoblastic leukaemia. Nature. 2007; 446: 758-764.

[20] Gu Z, Churchman ML, Roberts KG, Moore I, Zhou X, Nakitandwe J, et al. PAX5-driven subtypes of B-progenitor acute lymphoblastic leukemia. Nature Genetics. 2019; 51: 296-307.

[21] Shah S, Schrader KA, Waanders E, Timms AE, Vijai J, Miething $\mathrm{C}$, et al. A recurrent germline PAX5 mutation confers susceptibility to pre-B cell acute lymphoblastic leukemia. Nature Genetics. 2013; 45: 1226-1231.

[22] Golay J, D’Amico A, Borleri G, Bonzi M, Valgardsdottir R, Alzani R, et al. A Novel Method Using Blinatumomab for Efficient, Clinical-Grade Expansion of Polyclonal T Cells for Adoptive Immunotherapy. The Journal of Immunology. 2014; 193: 4739-4747.

[23] Wlodarska I, Aventín A, Inglés-Esteve J, Falzetti D, Criel A, Cassiman J, et al. A New Subtype of Pre-B Acute Lymphoblastic Leukemia with $\mathrm{t}(5 ; 12)(\mathrm{q} 31 \mathrm{q} 33 ; \mathrm{p} 12)$, Molecularly and Cytogenetically Distinct from $\mathrm{t}(5 ; 12)$ in Chronic Myelomonocytic Leukemia. Blood. 1997; 89: 1716-1722.

[24] Starkova J, Madzo J, Cario G, Kalina T, Ford A, Zaliova $\mathrm{M}$, et al. The identification of (ETV6)/RUNX1-regulated genes in lymphopoiesis using histone deacetylase inhibitors in ETV6/RUNX1-positive lymphoid leukemic cells. Clinical Cancer Research. 2007; 13: 1726-1735.

[25] Liu GJ, Cimmino L, Jude JG, Hu Y, Witkowski MT, McKenzie $\mathrm{MD}$, et al. Pax5 loss imposes a reversible differentiation block in B-progenitor acute lymphoblastic leukemia. Genes \& Development. 2014; 28: 1337-1350.

[26] Best A, Matheson E, Minto L, Hall AG, Irving JAE. Mismatch repair and the downstream target genes, PAX5 and Ikaros, in childhood acute lymphoblastic leukemia. Leukemia Research. 2010; 34: 1098-1102.

[27] Zhao Y, Aldoss I, Qu C, Marcucci G, Stein AS, Bhatia R, et al. Genomic Determinants of Response to Blinatumomab in Relapsed/Refractory (R/R) B-Cell Precursor Acute Lymphoblastic Leukemia in Adults. Blood. 2018; 132: 1552-1552.

[28] Mouttet B, Vinti L, Ancliff P, Bodmer N, Brethon B, Cario G, et al. Durable remissions in TCF3-HLF positive acute lymphoblastic leukemia with blinatumomab and stem cell transplantation. Haematologica. 2019; 104: e244-e247.

[29] Zhao Y, Aldoss I, Qu C, Crawford JC, Gu Z, Allen EK, et al. Tumor-intrinsic and -extrinsic determinants of response to blinatumomab in adults with B-all. Blood. 2021; 137: 471-484.

[30] Jain T, Litzow MR. No free rides: management of toxicities of novel immunotherapies in all, including financial. Blood Advances. 2018; 2: 3393-3403.

[31] Viardot A, Locatelli F, Stieglmaier J, Zaman F, Jabbour E. Concepts in immuno-oncology: tackling $\mathrm{B}$ cell malignancies with 
CD19-directed bispecific T cell engager therapies. Annals of Hematology. 2020; 99: 2215-2229.

[32] Curran E, O'Brien M. Role of blinatumomab, inotuzumab, and CAR T-cells: which to choose and how to sequence for patients with relapsed disease. Seminars in Hematology. 2020; 57: $157-$ 163.

[33] Hu Y, Zhou Y, Zhang M, Ge W, Li Y, Yang L, et al. CRISPR/Cas9-Engineered Universal CD19/CD22 DualTargeted CAR-T Cell Therapy for Relapsed/Refractory B-cell Acute Lymphoblastic Leukemia. Clinical Cancer Research. 2021; 27: 2764-2772.

[34] Dörfler P, Busslinger M. C-terminal activating and inhibitory domains determine the transactivation potential of BSAP (Pax5), Pax-2 and Pax-8. The EMBO Journal. 1996; 15: 1971-1982.

[35] Robichaud GA, Nardini M, Laflamme M, Cuperlovic-Culf M, Ouellette RJ. Human Pax-5 C-terminal Isoforms Possess Distinct Transactivation Properties and are Differentially Modulated in Normal and Malignant B Cells. Journal of Biological Chemistry. 2004; 279: 49956-49963.

[36] Haso W, Lee DW, Shah NN, Stetler-Stevenson M, Yuan CM, Pastan IH, et al. Anti-CD22-chimeric antigen receptors targeting B-cell precursor acute lymphoblastic leukemia. Blood. 2013; 121: 1165-1174.

[37] Kantarjian H, Stein A, Gökbuget N, Fielding AK, Schuh AC, Ribera J, et al. Blinatumomab versus Chemotherapy for Advanced Acute Lymphoblastic Leukemia. New England Journal of Medicine. 2017; 376: 836-847.

[38] von Stackelberg A, Locatelli F, Zugmaier G, Handgretinger R, Trippett TM, Rizzari C, et al. Phase I/Phase II Study of Blinatumomab in Pediatric Patients With Relapsed/Refractory Acute Lymphoblastic Leukemia. Journal of Clinical Oncology. 2016; 34: 4381-4389.

[39] Aldoss I, Song J, Stiller T, Nguyen T, Palmer J, O'Donnell M, et al. Correlates of resistance and relapse during blinatumomab therapy for relapsed/refractory acute lymphoblastic leukemia. American Journal of Hematology. 2017; 92: 858-865.

[40] European Medicines Agency (EMA). Blincyto. ????. Avaliable at: https://www.ema.europa.eu/en/medicines/human/EPA R/blincyto (Accessed: ).

[41] Kuchimanchi M, Zhu M, Clements JD, Doshi S. Exposureresponse analysis of blinatumomab in patients with relapsed/refractory acute lymphoblastic leukaemia and comparison with standard of care chemotherapy. British Journal of Clinical Pharmacology. 2019; 85: 807-817.

[42] Zou L, Zhang H, Du C, Liu X, Zhu S, Zhang W, et al. Correlation of SRSF1 and PRMT1 expression with clinical status of pediatric acute lymphoblastic leukemia. Journal of Hematology \& Oncology. 2012; 5: 42.

[43] Jamil A, Theil KS, Kahwash S, Ruymann FB, Klopfenstein KJ. TEL/AML-1 fusion gene. Its frequency and prognostic significance in childhood acute lymphoblastic leukemia. Cancer Genetics and Cytogenetics. 2000; 122: 73-78.

[44] Roberts KG, Pei D, Campana D, Payne-Turner D, Li Y, Cheng C, et al. Outcomes of Children with BCR-ABL1-Like Acute Lymphoblastic Leukemia Treated with Risk-Directed Therapy Based on the Levels of Minimal Residual Disease. Journal of Clinical Oncology. 2014; 32: 3012-3020.

[45] Depoil D, Fleire S, Treanor BL, Weber M, Harwood NE, Marchbank KL, et al. CD19 is essential for B cell activation by promoting $\mathrm{B}$ cell receptor-antigen microcluster formation in response to membrane-bound ligand. Nature Immunology. 2008; 9: 63-72.

[46] Davis JE, Sutton VR, Smyth MJ, Trapani JA. Dependence of granzyme B-mediated cell death on a pathway regulated by Bcl2 or its viral homolog, BHRF1. Cell Death \& Differentiation. 2000; 7: 973-983.

[47] Gu J, Li T, Zhao L, Liang X, Fu X, Wang J, et al. Identifica- tion of Significant Pathways Induced by PAX5 Haploinsufficiency Based on Protein-Protein Interaction Networks and Cluster Analysis in Raji Cell Line. BioMed Research International. 2017; 2017: 1-9.

[48] Yin H, Huo Y, Sheng Z, Li C, Ellwanger DC, Lu D, et al. Blinatumomab-Induced T Cell Activation at Single Cell Transcriptome Resolution. Blood. 2019; 134: 3886-3886.

[49] Duell J, Dittrich M, Bedke T, Mueller T, Eisele F, Rosenwald A, et al. Frequency of regulatory $\mathrm{T}$ cells determines the outcome of the T-cell-engaging antibody blinatumomab in patients with B-precursor all. Leukemia. 2017; 31: 2181-2190.

[50] Vignali DA, Collison LW, Workman CJ. How regulatory T cells work. Nature Reviews Immunology. 2008; 8: 523-532.

[51] Wei G, Wang J, Huang H, Zhao Y. Novel immunotherapies for adult patients with B-lineage acute lymphoblastic leukemia. Journal of Hematology \& Oncology. 2017; 10: 150.

[52] Huo Y, Sheng Z, Lu DR, Ellwanger DC, Li C, Homann O, et al. Blinatumomab-induced $\mathrm{T}$ cell activation at single cell transcriptome resolution. BMC Genomics. 2021; 22: 145.

[53] Zhou S, Liu M, Ren F, Meng X, Yu J. The landscape of bispecific T cell engager in cancer treatment. Biomarker Research. 2021; 9: 38.

[54] Feucht J, Kayser S, Gorodezki D, Hamieh M, Döring M, Blaeschke $\mathrm{F}$, et al. T-cell responses against CD19+ pediatric acute lymphoblastic leukemia mediated by bispecific Tcell engager (BiTE) are regulated contrarily by PD-L1 and CD80/CD86 on leukemic blasts. Oncotarget. 2016; 7: 7690276919.

[55] Schultz L, Gardner R. Mechanisms of and approaches to overcoming resistance to immunotherapy. Hematology. 2019; 2019: 226-232.

[56] Pillai V, Muralidharan K, Meng W, Bagashev A, Oldridge DA, Rosenthal J, et al. CAR T-cell therapy is effective for CD19dim B-lymphoblastic leukemia but is impacted by prior blinatumomab therapy. Blood Advances. 2019; 3: 3539-3549.

[57] Gardner RA, Finney O, Annesley C, Brakke H, Summers C, Leger K, et al. Intent-to-treat leukemia remission by CD19 CAR $\mathrm{T}$ cells of defined formulation and dose in children and young adults. Blood. 2017; 129: 3322-3331.

[58] Curran KJ, Margossian SP, Kernan NA, Silverman LB, Williams DA, Shukla N, et al. Toxicity and response after CD19-specific CAR T-cell therapy in pediatric/young adult relapsed/refractory B-all. Blood. 2019; 134: 2361-2368.

[59] Lee DW, Kochenderfer JN, Stetler-Stevenson M, Cui YK, Delbrook C, Feldman SA, et al. T cells expressing CD19 chimeric antigen receptors for acute lymphoblastic leukaemia in children and young adults: a phase 1 dose-escalation trial. The Lancet. 2015; 385: 517-528.

[60] Dourthe ME, Rabian F, Yakouben K, Chevillon F, CabannesHamy A, Méchinaud F, et al. Determinants of CD19-positive vs CD19-negative relapse after tisagenlecleucel for B-cell acute lymphoblastic leukemia. Leukemia. 2021; 35: 3383-3393.

[61] Denkert C, Huober J, Loibl S, Prinzler J, Kronenwett R, DarbEsfahani $\mathrm{S}$, et al. Her2 and ESR1 mRNA expression levels and response to neoadjuvant trastuzumab plus chemotherapy in patients with primary breast cancer. Breast Cancer Research. 2013; 15: R11.

[62] Iacobucci I, Li Y, Roberts KG, Dobson SM, Kim JC, PayneTurner D, et al. Truncating Erythropoietin Receptor Rearrangements in Acute Lymphoblastic Leukemia. Cancer Cell. 2016; 29: $186-200$

[63] Fischer U, Forster M, Rinaldi A, Risch T, Sungalee S, Warnatz HJ, et al. Genomics and drug profiling of fatal TCF3-HLFpositive acute lymphoblastic leukemia identifies recurrent mutation patterns and therapeutic options. Nature Genetics. 2015; 47: $1020-1029$. 